\title{
Increased Left Ventricular Stiffness Impairs Filling in Dogs with Pulmonary Emphysema in Respiratory Failure
}

\author{
A. Gomez and S. Mink \\ Section of Respiratory Diseases, University of Manitoba, Winnipeg, Manitoba, Canada R3E-0Z3
}

\begin{abstract}
In a chronic canine model of pulmonary emphysema, we studied the interaction between left ventricular (LV) mechanics and pulmonary disease during severe hypoxemia. The hypoxemia was similar to that which may occur during a severe exacerbation of chronic obstructive lung disease. In six dogs with papain-induced emphysema and in seven dogs without emphysema, LV mechanics were examined when a hypoxic gas mixture was inspired to reduce $\mathrm{PO}_{2}$ to about $35 \mathrm{mmHg}$ (hypoxic study) and during nonhypoxic conditions (room air study). In both groups, LV diastolic compliance was reduced during the hypoxic study by a similar amount. This finding could not be explained in terms of ventricular interdependence. Our analysis suggested that hypoxia decreased diastolic compliance (i.e., increased $\mathrm{LV}$ diastolic stiffness) by impairing $L V$ relaxation. The primary effect of hypoxia was to decrease the extent to which $L V$ relaxation occurred for a given end-diastolic pressure, while the rate of $L V$ relaxation was decreased just slightly. This study indicates that severe hypoxemia because of respiratory failure may impair myocardial relaxation leading to a decrease in $\mathrm{LV}$ filling.
\end{abstract}

\section{Introduction}

When severe hypoxemia develops during an acute exacerbation of chronic obstructive lung disease, changes in the diastolic as well as the systolic performance of the left ventricle may lead to a reduction in cardiac output. Systolic dysfunction could occur because of a decrease in myocardial contractility due to myocardial hypoxia. In that case, a reduction in ejection fraction would lead to a decrease in stroke volume (1). Alternatively, diastolic dysfunction may occur because of ventricular interaction and related pericardial effects (2-8). Increased right ventricular afterload and right ventricular filling may occur in response to pulmonary vasoconstriction during hypoxia (6-8), and the interventricular septum may move further toward the left ventricle during diastole. This change in septal position in conjunction with a relative increase in pericardial pressure could lead to a reduction in left ventricular compliance. Because enddiastolic volume would be reduced for a given end-diastolic pressure, a severe reduction in cardiac output may occur.

However, an additional mechanism that could lead to a decrease in left ventricular diastolic compliance in severely hypoxemic patients with chronic obstructive pulmonary disease

Address reprint requests to Dr. Mink, Respiratory Investigation Unit, F-2, Health Science Center, 700 William Avenue, Winnipeg, Manitoba R3E 0Z3, Canada.

Received for publication 15 January 1985 and in revised form 20 March 1986.

J. Clin. Invest.

(c) The American Society for Clinical Investigation, Inc.

0021-9738/86/07/0228/13 \$1.00

Volume 78, July 1986, 228-240
(COPD) relates to abnormalities in left ventricular relaxation. Ventricular relaxation (9-14) after contraction is an energy requiring process. Altered ventricular relaxation may develop when a supply-demand imbalance in myocardial oxygen occurs (9$13,15)$. In isolated heart preparations, previous investigators have shown that during anoxic conditions left ventricular diastolic pressure was increased relative to volume throughout diastole $(12,13,15)$. Under those conditions, Serizawa et al. (13) showed that the rate of decay in left ventricular pressure after contraction is decreased. Because systole could begin before the previous diastole was completed, resting end-diastolic pressure may not be reached. Additionally, however, there develops during anoxia increased ventricular diastolic stiffness that is independent of the rate of ventricular tension decay and that persists throughout diastole even at slow heart rates $(12,13,15)$. According to Serizawa et al. (13), this reduction in the extent of ventricular relaxation for a given pressure indicates incomplete or partial ventricular relaxation during hypoxia. Such a mechanism would therefore reduce ventricular end-diastolic volume relative to pressure, even if the length of diastole were quite long. The subcellular mechanisms that lead to changes in ventricular relaxation are not clear (9-13; see Discussion). However, the net result of these two effects (reduction in the rate and extent of relaxation) is that ventricular diastolic compliance may be decreased during hypoxia (16). Thus, during severe hypoxemia, changes in left ventricular relaxation may cause a decrease in ventricular filling and result in reduction of stroke volume.

Altered left ventricular relaxation has not been examined as a possible cause of left ventricular diastolic abnormalities during an acute severe exacerbation of COPD. Although such a mechanism is frequently cited to explain the decrease in ventricular diastolic compliance in the context of ischemic heart disease, when oxygen delivery to myocardium may be zero $(17,18)$, it is not clear whether the hypoxemia that occurs during an exacerbation of COPD would be severe enough to cause changes in left ventricular relaxation. Because relaxation variables are calculated from intraventricular pressure determinations (see Methods), it would be difficult to document that altered relaxation properties occurred in the clinical setting of respiratory decompensation.

In the canine lung, the enzyme papain instilled intrabronchially produces histologic changes analogous to those observed in patients with panacinar emphysema (19-22). In a previous

1. Abbreviations used in this paper: ANOVA, analysis of variance; BP, systemic arterial pressure; $\mathrm{CO}$, cardiac output; COPD, chronic obstructive pulmonary disease; ECG, electrocardiogram; EF, ejection fraction; HR, heart rate; LVEDP, left ventricular end-diastolic pressure; LVEDV, left ventricular end-diastolic volume; LVSP, peak left ventricular systolic pressure; $\overline{\text { Pap }}$, mean pulmonary artery pressure; PVR, pulmonary vascular resistance; $\overline{\mathrm{Pwp}}$, mean pulmonary capillary wedge pressure; $\overline{\mathrm{Rap}}$, mean right atrial pressure; $R V$, right ventricular; RVEDP, right ventricular end-diastolic pressure; RVEDV, right ventricular end-diastolic volume; RVSP, peak right ventricular systolic pressure; SV, stroke volume. 
study (20) in which this model was used, an elevation in mean pulmonary artery pressure comparable to that found in the stable COPD patient was achieved. In the present study, we examined the effect of hypoxic hypoxia on left ventricular performance in emphysematous dogs. Dogs in which emphysema was produced inspired a hypoxic gas mixture to reduce arterial oxygen tension to about $35 \mathrm{mmHg}$. This degree of hypoxemia was thought comparable to that observed in patient with COPD with an acute severe respiratory exacerbation. Ventricular and hemodynamic variables obtained during the administration of the hypoxic gas mixture (i.e., hypoxic hypoxia) were compared with those obtained when room air was inspired. A control group of dogs given saline solution intrabronchially was also studied during hypoxic hypoxia and on room air breathing. We therefore determined the change in left ventricular performance during hypoxic conditions, the relative effect of pulmonary emphysema, and the extent to which abnormalities in left ventricular relaxation contributed to the findings.

\section{Methods}

Emphysema model and resulting pulmonary function changes. The method to produce severe emphysema was as previously described (2022). In six dogs (emphysema group; weight $27-37 \mathrm{~kg}$ ), the enzyme papain (4 ml of type III [Sigma Chemical Co., St. Louis, MO] mixed in $36 \mathrm{ml}$ of normal saline) was instilled intrabronchially under bronchoscopic visualization into the lower lobe bronchi. Instillations were performed on a weekly basis and were alternated between the right and left lower lobes. Each lower lobe was instilled about seven times. For the instillation procedure, the animals were anesthetized with sodium pentobarbital (30 $\mathrm{mg} / \mathrm{kg}$ ). Immediately after the solution was instilled, the animal was placed on its side with the injured lobe placed dependently. Given in this manner, it was noted that the solution spread to the other lobes on the dependent side as well. The animals were mechanically ventilated while on their side (Harvard Apparatus Co., Inc., S. Natick, MA; 15 $\mathrm{ml} / \mathrm{kg}$ ) for 6-8 $\mathrm{h}$ inspiring $50 \%$ oxygen, and then returned to their cages. Antibiotics (penicillin and gentamicin) were given after the administration of papain and every $12 \mathrm{~h}$ thereafter for four doses to prevent infection. In seven control dogs (control group; weight $25-43 \mathrm{~kg}$ ), $40 \mathrm{ml}$ of normal saline solution was instilled in a similar manner.

To ascertain that severe emphysema was produced in the emphysema group, static lung volumes (total lung capacity and functional residual capacity) were measured prior to the first papain instillation and $\sim 2-4$ wk after all hemodynamic measurements had been made (see below). Pulmonary function measurements were obtained with the animals anesthetized (pentobarbital $30 \mathrm{mg} / \mathrm{kg}$ ) and placed in a volume displacement plethysmograph. The methodology was identical to that previously described $(20,23)$

Consistent with our former study (20), papain produced severe emphysematous changes. In the emphysema group, total lung capacity increased from $3.7 \pm 1$ to $6.9 \pm 1.7$ liters (mean $\pm \mathrm{SD}$ ), whereas the control group showed no changes in total lung capacity ( $4.0 \pm .9$ vs. $4.1 \pm 0.8$ liters; total lung capacity in the emphysema group was significantly greater than in the control group at the end of the study; $P<0.05$ by unpaired $t$ test). Further, because of the loss in lung elasticity, pleural surface pressure measured at functional residual capacity was slightly more positive in the emphysema group $\left(0.6 \pm 1.4 \mathrm{cmH}_{2} \mathrm{O}\right)$ than in the control group $\left(-1.4 \pm 2.2 \mathrm{cmH}_{2} \mathrm{O}\right.$; mean $\pm \mathrm{SD}, P<0.05$ by unpaired $t$ test). Vascular measurements were obtained at functional residual capacity (see below) where there would be little change in lung recoil with increases in vascular volume (24). If pleural pressure were considered the external pressure around the heart and intrathoracic vessels, then pleural surface pressure would need to be subtracted from the hemodynamic measurements to obtain transmural pressures. However, the difference in pleural surface pressure between the two groups was small, and the use of transmural pressure would add little to the study (see Results).

General protocol of the hemodynamic studies. In each of the em- physema and control groups, two hemodynamic studies were performed. During one study, the animals inspired room air (room air study), while in the other study a hypoxic gas mixture was inspired (hypoxic study). The initial hemodynamic study was performed $\sim 3-4$ wk after the final papain or saline instillation, and the second hemodynamic study was performed $\sim 1$ mo after the first. The order of the hemodynamic studies within each group was randomized, and the dogs from the respective groups were examined alternately. Based on our previous experience with this model (20), the emphysema lesion is rather stable over the time period between the initial hemodynamic and final lung mechanic studies (6-8 wk). Further, it was believed that the animals would not tolerate measurements obtained at shorter intervals. The protocol was approved by the animal care committee, and the animals were housed under their care.

During the hypoxic study, measurements were made during three conditions: baseline $\left(B_{1}\right)$; hypoxia $(H)$; and volume-loaded hypoxia $(\mathrm{VH})$. Baseline measurements $\left(B_{1}\right)$ were performed while the animals inspired room air. The animals were then switched to a gas mixture of low oxygen concentration to reduce $\mathrm{PO}_{2}$ from that obtained at $\mathrm{B}_{1}$ to about $35 \mathrm{mmHg}$ (condition $\mathrm{H}$ ). Because $\mathrm{PO}_{2}$ at $\mathrm{B}_{1}$ varied between the groups, the inspired oxygen concentration of the hypoxic gas mixture also varied. For the final condition during the hypoxic study, the animals were given an intravascular volume load of $6 \%$ hetastarch in normal saline solution $(35 \mathrm{ml} / \mathrm{kg}$ ) while still inspiring the hypoxic gas mixture (VH).

During the room air study, only two conditions were examined. Initially, baseline $\left(B_{2}\right)$ measurements were again determined as in the hypoxic study (labeled $B_{2}$ to differentiate these measurements from those obtained during the hypoxic study termed $B_{1}$, but recognizing that $B_{1}$ and $B_{2}$ were performed under identical conditions); volume loading with $6 \%$ hetastarch was then performed as in the hypoxic study $(\mathrm{V})$, and measurements were again made while the animals breathed room air.

Measurements. Hemodynamic measurements were obtained with the animals anesthetized with sodium pentobarbital $(30 \mathrm{mg} / \mathrm{kg})$, intubated with an endotracheal tube, mechanically ventilated $(15 \mathrm{ml} / \mathrm{kg})$, and paralyzed with succinylcholine $(2 \mathrm{ml} ; 20 \mathrm{mg} / \mathrm{ml})$. All variables were obtained at end expiration and therefore at functional residual capacity with the animal in the supine position. The procedures were performed under sterile conditions.

The methodology to obtain indexes of central hemodynamics and cardiac mechanics was the same during each study. The ventilator rate was set to maintain $\mathrm{PCO}_{2}$ at about $35 \mathrm{mmHg}$ at the beginning of the study. A polyethylene catheter was placed into a femoral artery for obtaining samples of arterial blood and for measuring systemic arterial pressure (BP). A large bore catheter was placed into the femoral vein for volume loading with $6 \%$ hetastarch in normal saline solution $(35 \mathrm{ml} /$ $\mathrm{kg}$ ). A thermister-tipped double-lumen Swanz-Ganz catheter (no. 7, Edwards, Santa Ana, CA) was used to determine mean pulmonary artery pressure $(\overline{\mathrm{Pap}})$, mean pulmonary capillary wedge pressure $(\overline{\mathrm{Pwp}})$, and to obtain cardiac output (CO) by thermodilution with a cardiac output computer (Columbus Instruments, Columbus $\mathrm{OH}$ ). A second SwanzGanz catheter was placed into the right atrium for obtaining mean right atrial pressure $(\overline{\mathrm{Rap}})$ and for injecting the cold saline boluses for the cardiac output determinations. The average of five to six cardiac output determinations were obtained during each condition, measured also at end expiration. With the animal in the supine position, zero pressure reference was taken as the left atrium. Statham transducers (Hato Rey, PR) were used to record vascular pressures. The outputs of all recordings were displayed on a eight-channel Hewlett-Packard recorder (Palo Alto, CA).

Measurements of left (LVEDP) and right end-diastolic pressures (RVEDP) and left (LVSP) and right peak systolic pressures (RVSP) were made with high-fidelity transducer-tipped catheters (no. 7, Millar instruments, Houston, TX). Millar catheters were advanced into the left and right ventricles through incisions made in the carotid artery and external jugular vein, respectively. The maximal rate of rise of the pressure signal $(\mathrm{d} p / \mathrm{d} t)$ from each ventricle was used as an index of contractility. Continuous electrocardiogram (ECG) recordings were used to obtain heart rate $(\mathrm{HR})$ and to determine the onset of systole. 
The rate of left ventricular relaxation was determined by two methods $(10,14)$. The isovolumic relaxation period was defined as the period from time of minimum $\mathrm{d} p / \mathrm{d} t$ to the time when left ventricular pressures fell to $5 \mathrm{mmHg}$ above the end-diastolic pressure of the following beat (10). Weiss et al. (10) proposed that, if the fall in intraventricular pressure could be analyzed as a monoexponential equation with a time constant (T), then $P=P o \mathrm{e}^{-t / T}$, where $P$ is intracavitary pressure, $P o$ is the intracavitary pressure at minimum $\mathrm{d} p / \mathrm{d} t, t$ is time, and $T$ is the time constant. Alternatively, Raff and Glantz (14) thought that this method was subject to errors resulting from external pressures applied to the heart via the pleura and pericardium, as well as to the fact that the fully relaxed left ventricle may not have a zero pressure. To account for these factors, they included the parameter $P b$ in their analysis. The formula suggested by Raff and Glantz is given by $P=P o \mathrm{e}^{-t / T}+P b$. The relaxation variables reported represent the average of those obtained over four beats.

Radionuclide angiography techniques were initially used to determine left and right ventricular ejection fractions and to ascertain ventricular performance in each condition. (Subsequently, endocardial ultrasonic crystals were also used in acute experiments, see subsection below: Supplemental studies.) For the left ventricle, radionuclide angiography methods similar to those described by Swain et al. (25) and Sodums et al. (26) were used, while for the right ventricle the method of Kay et al. (27) was used. Gated equilibrium radionuclear angiograms were obtained after in vivo red cell labeling with $40 \mathrm{mCi}$ technetium-99m after the intravenous administration of stannous pyrophosphate. The dogs were maintained in the supine position. A mobile gamma camera (Picker Corp., Northford, CT) equipped with a parallel hole collimator was oriented in the left anterior oblique position, where the interventricular septum was clearly visible on the oscilloscope display of the blood pool in the heart. Caudal angulation of $5-15^{\circ}$ was used as needed to obtain chamber separation. Image acquisition allowed count information to be stored in frames of each cardiac cycle ( 32 per cycle) in a computer (MDS; $\mathrm{A}^{2}$ hardware and software). The cardiac cycle was displayed on a video screen which allowed end-diastolic and end-systolic frames to be identified. Each frame contained at least 250,000 counts. Left and right ventricular end-diastolic and end-systolic regions of interest were assigned with a light pen. Background substracted, time-activity curves were generated for each ventricle. Separation of the right and left ventricles from the respective atria was aided by reference to first pass flow studies recorded in the left anterior oblique position at the beginning of the study to obtain the best views, and to phase contrast techniques. Ejection fractions (EF) were calculated as the difference between end-diastolic and end-systolic counts divided by end-diastolic counts after appropriate background corrections. Stroke volume (SV) was obtained from $\mathrm{CO}$ / HR. End-diastolic volume (EDV) was calculated from EDV $=S V / E F$.

Samples of arterial and mixed venous blood were drawn from the femoral artery catheter and Swan-Ganz catheter, respectively during each condition. The samples were analyzed for oxygen and carbon dioxide tensions $\left(\mathrm{PO}_{2}\right.$ and $\left.\mathrm{PCO}_{2}\right)$ and $\mathrm{pH}$ with a Corning 165-2 (Medfield, MA) blood gas analyzer.

After completion of each study, the animals were placed on $100 \%$ oxygen and the vascular accesses surgically closed. All vascular accesses were closed wtih no. 6-0 proline suture and skin wounds were closed with no. 3-0 silk. To ensure that recovery was complete after each study period, the animals were watched until recovery from anesthesia was complete. Especially during the hypoxic study, measurements were performed as quickly as possible $(0.5-1.0 \mathrm{~h})$. Two animals in the emphysema group (dogs 4 and 6; see Figs. 4 and 6) bled excessively after the hypoxic study and were killed. The other dogs awakened from anesthesia without difficulty and were returned to their cages where they presently remain.

Supplemental experiments performed to corroborate the radionuclide angiography findings. To further substantiate the cardiac findings obtained with radionuclide angiography techniques (see Results), subsequent acute canine experiments were performed in which endocardial ultrasonic crystals were used to measure end-diastolic and end-systolic dimensions of the right and left ventricles during room air breathing and at a $\mathrm{PO}_{2}$ of $35 \mathrm{mmHg}$. In this technique, the transit time of bursts of high frequency ultrasound between transducer pairs (ultrasonic crystals) is proportional to distance $(25,26,28)$. These experiments were performed on animals separate from those in the emphysema and control groups. These dogs did not have emphysema and were sacrificed after the experiment.

To examine left ventricular dimensions in response to a $\mathrm{PO}_{2}$ of 35 $\mathrm{mmHg}$, endocardial ultrasonic crystals were used in six canine experiments. The animals were anesthetized and paralyzed as previously described (pentobarbital, $30 \mathrm{mg} / \mathrm{kg}$; succinycholine, $40 \mathrm{mg}$ ); their chests and pericardia were widely opened. The animals were placed on $5 \mathrm{cmH}_{2} \mathrm{O}$ positive end expiration; otherwise the preparation was as described in the emphysema study. Ultrasonic crystals (hemispheric ceramic transducers, Channel Industries, Santa Barbara, CA) were implanted in three dimensions: anterior-posterior $(n=6)$, apex to base $(n=6)$, and septal to lateral free wall $(n=4)$. The endocardial placement of the three pairs of crystals and the technique of positioning the septal to free wall pair were performed as described by Robotham et al. (28). The three pairs of crystals were attached to individual channels on a sonomicrometer (Sonomicrometer 120, Triton Technology, San Diego, CA). The outputs of the three channels were displayed on an oscillograph (Hewlett Packard), from which end-diastolic and end-systolic dimensions were obtained. Measurements were obtained with the animal volume-loaded to a pulmonary capillary wedge pressure of $\sim 12 \mathrm{mmHg}$. Left ventricular dimensions, ECG recordings, arterial and mixed venous gas tensions, mean systemic blood pressure, and mean right atrial and pulmonary capillary wedge pressures were determined with the animal breathing room air and then a hypoxic gas mixture to lower $\mathrm{PO}_{2}$ to $\sim 35 \mathrm{mmHg}$. The animals inspired the hypoxic gas mixture for $\sim 15-30$ min before measurements were obtained. The crystal positions were checked after the animals were sacrificed.

To further evaluate right ventricular performance during acute hypoxemia, to examine whether the septum moved to the left during this condition, a pair of endocardial ultrasonic crystals was used to measure the distance between the right ventricular free wall (anterior aspect) and the right ventricular side of the septum in four other dogs. The method to seat the free-wall and septal crystals on the endocardium of the right ventricle was similar to that used to position the septal-lateral crystal pair in the left ventricular study. The retrograde placement technique described by Robotham et al. (28) was used, in which a special needle was passed through the anterior aspect of right ventricular free wall, through the septum, and then pulled out of the left ventricle along its anterior wall. The wires of the septal crystal were pulled through the septum and out the left ventricle with the needle. The septal crystal was seated on the right ventricular side of the septum about one-half way down the septal length. The right ventricular free wall crystal was seated on the endocardium, through the stab wound made on the anterior surface of the right ventricle used to seat the septal crystal. The anterior stab wound was placed as close to the right atrium as possible to maximize the septal to free wall dimensions. Besides the crystal positioning, the preparation and protocol for the dogs in the right ventricle crystal study was the same as that described for the left. The crystal positions were checked at autopsy.

Statistical analysis. In the emphysema study, a two-way analysis of variance (ANOVA) was used to determine statistical significance (statistical analysis system [SAS]: General Linear Models, type 3 estimation). There were two independent variables: groups (two levels: emphysema and control groups) and conditions (five levels: $B_{1}, H, V H, B_{2}, V$ ). The ANOVA used was a between-within two-factor mixed design ("splitplot"), in that between-subject (groups) and within-subject comparisons (five levels of conditions) were obtained. A Tukey's Studentized range test was used to examine for significant differences between conditions. When other statistical tests were used, these tests are indicated in the text.

\section{Results}

\section{Emphysema study}

Hemodynamic findings during hypoxia. Fig. 1 shows the blood gas variables obtained in the different conditions in the emphy- 

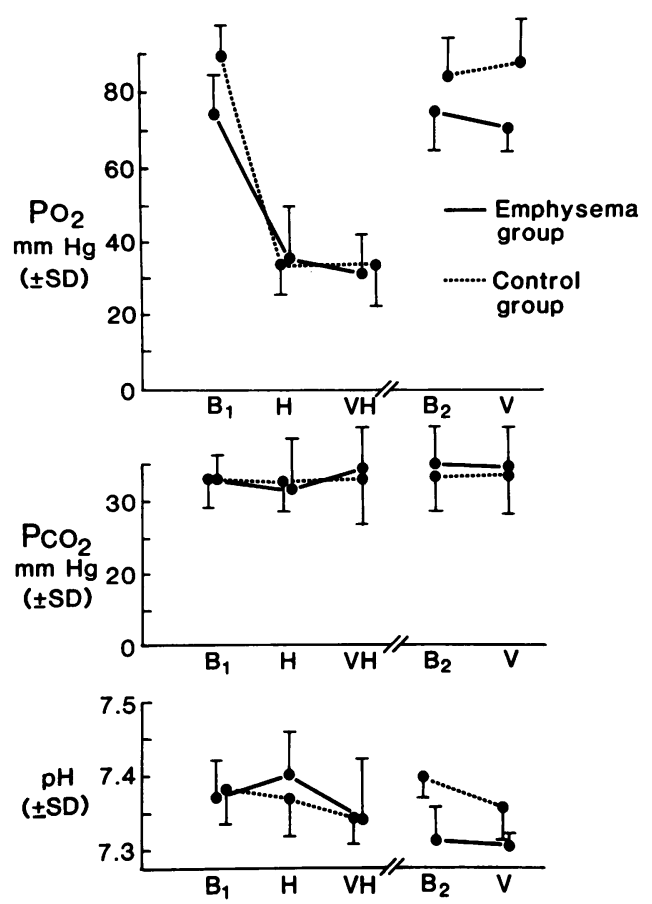

Figure 1. Mean ( $\pm \mathrm{SD})$ arterial blood oxygen tensions $\left(\mathrm{PO}_{2}\right)$, arterial carbon dioxide $\left(\mathrm{PCO}_{2}\right)$ tensions, and $\mathrm{pH}$ obtained in the various conditions for the emphysema and control groups are shown. Parameters were obtained during the hypoxic study $\left(B_{1}\right.$, baseline with the animals breathing room air; $\mathrm{H}$, breathing the hypoxic gas mixture; $\mathrm{VH}$, breathing the hypoxic gas mixture in the volume-loaded condition) and at the room air study $\left(B_{2}\right.$, baseline breathing room air; $V$, breathing room air in the volume-loaded condition).

sema and control groups. Mean $\mathrm{PO}_{2}$ at baseline $\left(\mathrm{B}_{1}\right)$ was about $15 \mathrm{mmHg}$ lower in the emphysema group, with almost no overlap of $\mathrm{PO}_{2}$ between the two groups in this condition. However, during hypoxia (i.e., $\mathrm{H}$ and $\mathrm{VH}$ ), $\mathrm{PO}_{2}$ in each group was fixed around $35 \mathrm{mmHg}$, while $\mathrm{PCO}_{2}$ was fixed at about $35 \mathrm{mmHg}$ at baseline $\left(B_{1}\right)$. There were no differences in blood gas variables between groups, but because many of the end-points were predetermined, respiratory gas exchange differences between groups become difficult to assess. $\mathrm{PCO}_{2}$ and $\mathrm{pH}$ in the two groups were not significantly different between conditions. For each group, the central hemodynamic and cardiac indexes obtained in the various conditions are shown in Fig. 2 and Table I, respectively. Mean pulmonary artery pressure at baseline $\left(\mathrm{B}_{1}\right.$ and at all conditions) was $\sim 10 \mathrm{mmHg}$ higher in the emphysema group than in the control group $(P<0.05$; see Fig. 2$)$. Peak right ventricular systolic pressure at baseline ( $B_{1}$ and at all conditions) was also about $10 \mathrm{mmHg}$ greater in the emphysema group $(P<0.05$; see Table I).

When the hypoxic gas mixture was inspired $\left(B_{1}\right.$ to $H$; see Fig. 2), mean $\widehat{\text { Pap }}$ increased $\sim 13 \mathrm{mmHg}$ in the emphysema group and about $11 \mathrm{mmHg}$ in the control group. After volume was administered intravenously (from $\mathrm{H}$ to $\mathrm{VH}$ and from $\mathrm{B}_{2}$ to V; see Fig. 2 and Table I), there were large increases in right and left ventricular filling pressures, which also occurred to a similar extent in both groups. Although multiple measurements were obtained, when the hypoxic and room air studies are compared, the important findings to note in interpreting the different hemodynamic findings between the two studies (see below) are that left ventricular filling pressures (i.e., $\overline{\text { Pwp }}$, Fig. 2; and

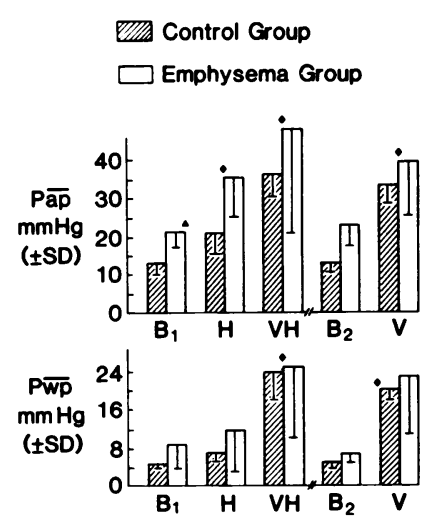

Figure 2. Hemodynamic variables are shown for the emphysema ( $\square$ ) and control ( $\square$ ) groups during the hypoxic study (conditions $\mathrm{B}_{1}, \mathrm{H}$, and $\mathrm{VH}$ ) and during the room air study (conditions $\mathrm{B}_{2}$ and $\mathrm{V}$ ). See Fig. 1 for the labeling of the conditions. $\overline{\text { Pap }}$, mean pulmonary artery pressure; $\overline{\mathrm{P} w p}$, mean pulmonary capillary wedge pressure; $\overline{\mathrm{Rap}}$, mean right atrial pressure; $\overline{\mathrm{BP}}$, mean systemic blood pressure (mean \pm SD). Two-way ANOVA and Tukey's multiple comparison test were used to determine statistical signifcance. By this analysis, $\overline{\text { Pap }}$ was significantly different between

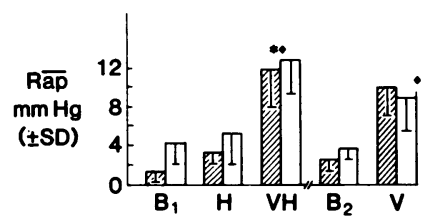
the two groups $(P<0.05)$ over all the conditions shown. Between the hypoxic and room air studies, $\overline{\operatorname{Rap}}$ was significantly different between the volume-loaded hypoxic and room air conditions (*indicates $P<0.05 ; \mathrm{V}$ vs. VH). In each

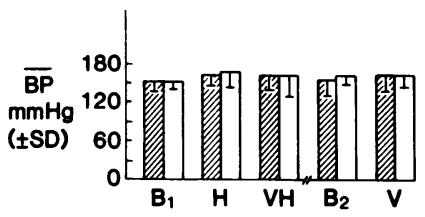
study, those conditions marked $(\bullet)$ were significantly different $(P<0.05)$ from the condition immediately preceding.

LVEDP, Table I) at comparable conditions were about the same or even slightly higher during the hypoxic study than during the room air study.

The cardiac outputs obtained in hypoxic and room air studies in the various conditions are shown in Fig. 3. During the hypoxic study, cardiac outputs at baseline $\left(B_{1}\right)$ were similar in the emphysema and control groups, and there was almost no change in cardiac output from baseline to hypoxia (i.e., $B_{1}$ to $H$ ). The cardiac output obtained in the volume-loaded condition during the hypoxic study was less than during the room air study in each group (compare VH vs. V in Fig. 3). In the emphysema group, with volume administration, the increase in cardiac output during hypoxia (mean $\pm \mathrm{SD}$ ) was from $3.8 \pm 1.4 \mathrm{liter} / \mathrm{min}$ to $5.0 \pm 1$ liter/min (i.e., from $\mathrm{H}$ to $\mathrm{VH}$ ). This contrasts to the findings at the room air study in which the increase in cardiac output was much higher with hydration, and cardiac output increased in the emphysema group from $4.2 \pm 1$ to $8.6 \pm 1.7 \mathrm{liter} / \mathrm{min}$ (see $B_{2}$ to $V$ in Fig. 3).

In that heart rate did not differ significantly between the volume-loaded hypoxic and room air conditions (see Table I), the differences in cardiac output were due to differences in SV. Both groups showed similar findings in SV during hypoxia. The increase in SV during hypoxia (i.e., from $\mathrm{H}$ to $\mathrm{VH}$ ) was smaller than during room air breathing in both groups. In the emphysema group, the increase in SV during hypoxia (i.e., from $\mathrm{H}$ to $\mathrm{VH}$-mean $\pm \mathrm{SD}$ ) was from $26 \pm 11$ to $34 \pm 11 \mathrm{ml}$, whereas during room air the increase was from $24 \pm 5$ to $51 \pm 7.7 \mathrm{ml}$. In the control group, the increases were from $30 \pm 8$ to $43 \pm 7 \mathrm{ml}$ and from $24 \pm 12.4$ to $54 \pm 10 \mathrm{ml}$, respectively (SV:V vs. VH was significantly different, $P<0.05$ by ANOVA and Tukey's multiple comparison test). 


\begin{tabular}{|c|c|c|c|c|c|c|c|c|c|c|}
\hline & \multicolumn{5}{|c|}{ Emphysema group } & \multicolumn{5}{|c|}{ Control group } \\
\hline & \multicolumn{3}{|c|}{ Hypoxia study } & \multicolumn{2}{|c|}{ Room air study } & \multicolumn{3}{|c|}{ Hypoxia study } & \multicolumn{2}{|c|}{ Room air study } \\
\hline & $\mathbf{B}_{1}$ & $\mathbf{H}$ & VH & $\mathbf{B}_{\mathbf{2}}$ & $\mathbf{v}$ & $\mathbf{B}_{1}$ & $\mathbf{H}$ & VH & $\mathbf{B}_{2}$ & $\mathbf{v}$ \\
\hline HR (beats/min) & $163 \pm 36$ & $153 \pm 19$ & $153 \pm 32$ & $173 \pm 29$ & $167 \pm 21$ & $150 \pm 17$ & $133 \pm 28$ & $141 \pm 24$ & $156 \pm 21$ & $152 \pm 19$ \\
\hline RVEDP $(\mathrm{mmHg})$ & $4.2 \pm 4$ & $6.6 \pm 4.5$ & $14.7 \pm 5 \ddagger$ & $3.4 \pm 1.9$ & $10.4 \pm 6.2 \ddagger$ & $1 \pm 3.5$ & $3.5 \pm 3.0$ & $9.8 \pm 4.7 \ddagger$ & $2.6 \pm 3.1$ & $8.9 \pm 6.9 \ddagger$ \\
\hline LVEDP $(\mathrm{mmHg})$ & $9.3 \pm 5.4$ & $11.2 \pm 7.3$ & $25 \pm 14 \ddagger$ & $7 \pm 2.4$ & $24 \pm 15 \ddagger$ & $4.9 \pm 1.3$ & $6.9 \pm 2.0$ & $24 \pm 13 \ddagger$ & $4.8 \pm 1.9$ & $19 \pm 2.2 \ddagger$ \\
\hline LVSP $(m m H g)$ & $166 \pm 20$ & $177 \pm 22$ & $161 \pm 27$ & $169 \pm 21$ & $179 \pm 12$ & $158 \pm 18$ & $176 \pm 23$ & $176 \pm 25$ & $166 \pm 41$ & $166 \pm 22$ \\
\hline RVSP ( $m m H g)$ & $38.8 \pm 11^{*}$ & $48 \pm 13 \ddagger$ & $57 \pm 12.4 \ddagger$ & $35 \pm 6$ & $56 \pm 21 \ddagger$ & $28.3 \pm 5.1$ & $36 \pm 11 \ddagger$ & $48 \pm 10 \ddagger$ & $29 \pm 9$ & $41 \pm 6.0 \ddagger$ \\
\hline PVR $(\mathrm{mmHg} /$ liter $\cdot \min )$ & $3.62 \pm 1.9$ & $5.83 \pm 2.5 \ddagger$ & $5.20 \pm 4.1$ & $3.85 \pm 1.04$ & $2.17 \pm 0.8$ & $2.09 \pm 1.0$ & $3.85 \pm 0.8 \ddagger$ & $2.2 \pm 0.8$ & $2.2 \pm 0.9$ & $1.88 \pm 0.75$ \\
\hline $\operatorname{RVEDV}(m l)$ & $47 \pm 7.7$ & $51 \pm 22$ & $80 \pm 33 \ddagger$ & $47 \pm 12$ & $92 \pm 21 \ddagger$ & $54 \pm 13$ & $52 \pm 13$ & $84 \pm 33 \ddagger$ & $51 \pm 16$ & $99 \pm 26 \ddagger$ \\
\hline
\end{tabular}

For definitions of abbreviations, see abbreviations footnote. Values are given as mean \pm SD. $B_{1}, H$, and VH were obtained at the hypoxic study. $\mathrm{H}$ and $\mathrm{VH}$ were obtained on a hypoxic gas mixture before and after volume loading, respectively. $B_{1}$ was obtained on room air ( $n=7$ in the control group, $n=6$ in the emphysema group). $B_{2}$ and $V$ were obtained on room air (room air study) before and after volume loading, respectively ( $n=7$ in the control group, $n=4$ in the emphysema group). $* P<0.05$ emphysema group vs. the control group by two-way ANOVA. $¥ P<0.05$ from preceding condition (Tukey's multiple comparison test).

In Fig. 4, SV is plotted against LVEDP for the individual dogs in the two groups. In the hypoxic study, the coordinates were obtained before and after volume expansion with the animals inspiring a hypoxic gas mixture (i.e., $\mathrm{H}$ and $\mathrm{VH}$ ), whereas in the room air study, the coordinates were obtained before and after volume expansion while the animals inspired room air (i.e., $B_{2}$ and V). With hydration, the increase in SV relative to the increase in LVEDP $(\Delta$ SV/ $\triangle$ LVEDP) during the room air study was greater than during the hypoxic study in both groups. The mean $( \pm \mathrm{SD})$ slopes of these plots, hypoxic vs. room air study, were $0.97 \pm 0.97$ vs. $1.93 \pm 1.33 \mathrm{ml} \mathrm{SV} / \mathrm{mmHg}$ LVEDP in the emphysema group and $0.85 \pm 0.92$ vs. $1.84 \pm 0.82$ $\mathrm{ml} \mathrm{SV} / \mathrm{mmHg}$ LVEDP in the control group (the slope during the hypoxic study was significantly less than during the room air study by paired $t$ test $[P<0.001]$. This analysis included those dogs $[n=11]$ for which both studies were completed; there were no differences between groups). Thus, in both groups, the left ventricular function curve as assessed by the relationship of SV to LVEDP was shifted downward and to the right (i.e., depressed) during hypoxia.

\section{Control Group}

\section{Emphysema Group}

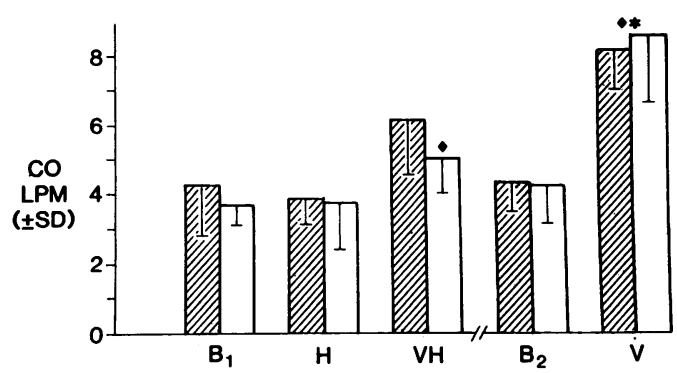

Figure 3. The mean $( \pm \mathrm{SD})$ cardiac outputs $(\mathrm{CO})$ obtained during the hypoxic study (conditions $\mathrm{B}_{1}, \mathrm{H}$, and $\mathrm{VH}$ ) and room air study (conditions $B_{2}$ and $V$ ) for the emphysema ( $(\square)$ and control ( $(0)$ groups are shown. See Fig. 1 for the labeling of conditions. By two-way ANOVA and Tukey's multiple comparison test, cardiac output was not different between groups. Cardiac output in the volume-loaded room air condition $(V)$ was significantly higher $\left({ }^{*}\right.$ indicates $\left.P<0.05\right)$ than in the volume-loaded hypoxic condition (VH). In each study, those conditions marked $(\bullet)$ were significantly different from the condition immediately preceding $(P<0.05)$. LPM, liters per minute.

\section{Emphysema Group}

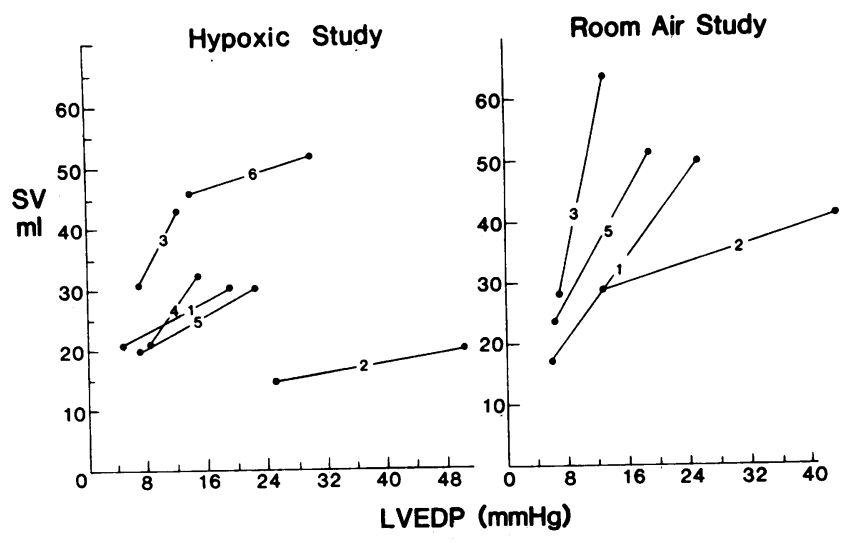

Control Group

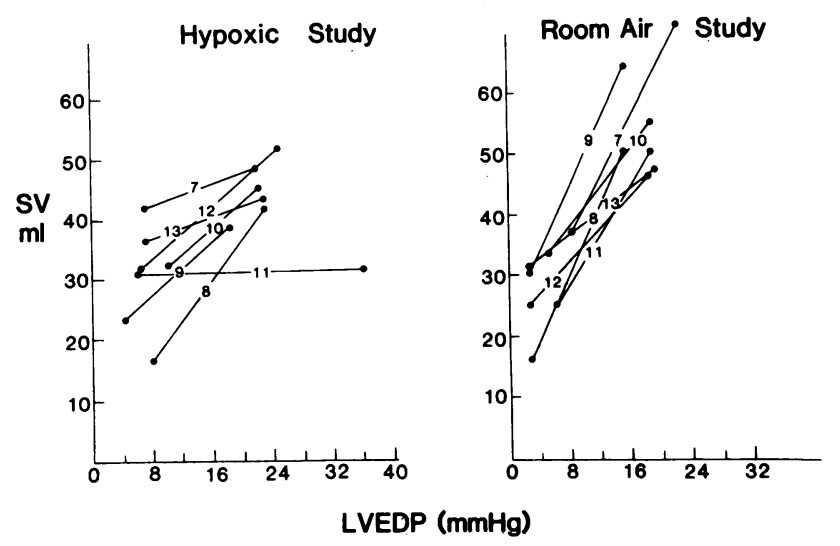

Figure 4. Stroke volume $(\mathrm{SV}, \mathrm{ml})$ is plotted against left ventricular end-diastolic pressure (LVEDP, $\mathrm{mmHg}$ ) for the individual dogs in the emphysema (dogs 1-6) and control (dogs 7-13) groups during the hypoxic and room air studies. The SV and LVEDP plotted were obtained at low and at high levels of intravascular hydration with the animals breathing room air $\left(B_{2}, V\right)$ and the hypoxic gas mixture $(H$, VH). SV in the volume-loaded condition was significantly higher $(P$ $<0.05$ ) on room air breathing than on the hypoxic gas mixture. The slope of the SV to LVEDP relationship ( $\triangle$ SV/D LVEDP) obtained during the hypoxic study was depressed (shifted to the right) compared with the room air study for the individual dogs in both groups. The mean slope obtained during hypoxia was about one half that obtained during room air breathing in both groups (see text for details). 
In each group, the smaller increase in cardiac output and SV after volume loading during the hypoxic study was not due to a relative decrease in left ventricular filling pressure or to a change in left ventricular afterload. In the volume-loaded condition, $\overline{\text { Pwp }}, \overline{\mathrm{BP}}$ (see Fig. 2), and LVEDP (see Table I) were about the same in the two studies in the respective groups (compare V vs. VH).

Indices of left ventricular performance. The reduced SV in the volume-loaded hypoxic condition relative to the room air condition (i.e., VH and V) was examined to determine whether it was due to a reduction in the systolic or diastolic performance of left ventricle during the hypoxic study. To examine for a change in systolic performance, a Frank-Starling relationship was constructed. In Fig. 5, SV is plotted against LVEDV for those dogs in the emphysema (dogs $1-3,5)$ and control groups (dogs 7-10, 12-13) for which both studies were completed. The coordinates shown in this figure were obtained in the pre- and post-volume-loaded conditions during hypoxia ( $\mathrm{H}$ and $\mathrm{VH}$ ) and during room air breathing $\left(\mathrm{B}_{2}\right.$ and $\left.\mathrm{V}\right)$. All conditions considered, the coordinates appear to describe a single linear relationship for most dogs. This finding would suggest a single Frank-Starling relationship and thus unchanged systolic function between studies. As an index of systolic function, the relationship of SV to LVEDV ( $\Delta \mathrm{SV} / \Delta \mathrm{LVEDV})$ was calculated during each study for each group. The increases in SV and LVEDV between the pre- and post-volume-loaded conditions during each study were used to derive this relationship. $\Delta S V / \Delta L V E D V$ was very similar between studies in the respective groups. In the emphysema group, $\Delta \mathrm{SV} / \Delta \mathrm{LVEDV}$ was (mean $\pm \mathrm{SD}$ ) $0.50 \pm 0.21 \mathrm{ml}$ of SV/ $\mathrm{ml}$ of LVEDV during the hypoxic study and $0.57 \pm 0.22 \mathrm{ml}$ of $\mathrm{SV} / \mathrm{ml}$ of LVEDV during the room air study. The results in the control group were $0.65 \pm 0.38$ and $0.65 \pm 0.32 \mathrm{ml}$ of $\mathrm{SV} / \mathrm{ml}$ of LVEDV, respectively. This analysis would indicate that systolic function was unchanged between the two studies. Compared with the room air study, the reduced $\mathbf{S V}$ after hydration during the hypoxic study could be explained by a corresponding reduction in LVEDV. Other parameters of systolic function $(\mathrm{d} p /$ $\mathrm{d} t$ and EF; see Table II) also did not change between the volumeloaded hypoxic and room air conditions, and thus there was no evidence to suggest a reduction in systolic performance of the left ventricle as a mechanism for the reduction in stroke volume.

However, for similar end-diastolic pressures after hydration during the hypoxic and room air studies, LVEDV was significantly reduced during the volume-loaded hypoxic condition in the two groups. In the emphysema group, LVEDV (mean \pm SD) was $67 \pm 5 \mathrm{ml}$ during the volume-loaded hypoxic condition and $94 \pm 27 \mathrm{ml}$ during the volume-loaded room air condition. The results in the control group were $82 \pm 14 \mathrm{ml}$ and $109 \pm 34 \mathrm{ml}$, respectively ( $P<.05 \mathrm{~V}$ vs. VH by ANOVA and Tukey's comparison test).

In Fig. 6, LVEDP is plotted against LVEDV for the individual dogs in the two groups. The coordinates shown were obtained during hypoxia ( $\mathrm{H}$ and $\mathrm{VH})$ and during room air breathing $\left(\mathbf{B}_{2}\right.$ and V). Compared with the room air study, the diastolic pressurevolume relationship of the left ventricle in all dogs was shifted upward and to the left during the hypoxic study. The relationship of LVEDP to LVEDV represents the diastolic elastance (1/compliance) of the left ventricle. The upward shift during the hypoxic study would indicate that the diastolic elastance of the left ventricle increased during hypoxia in both groups (i.e., increased diastolic stiffness or decreased compliance). This increase in diastolic elastance resulted in a reduced LVEDV and hence SV

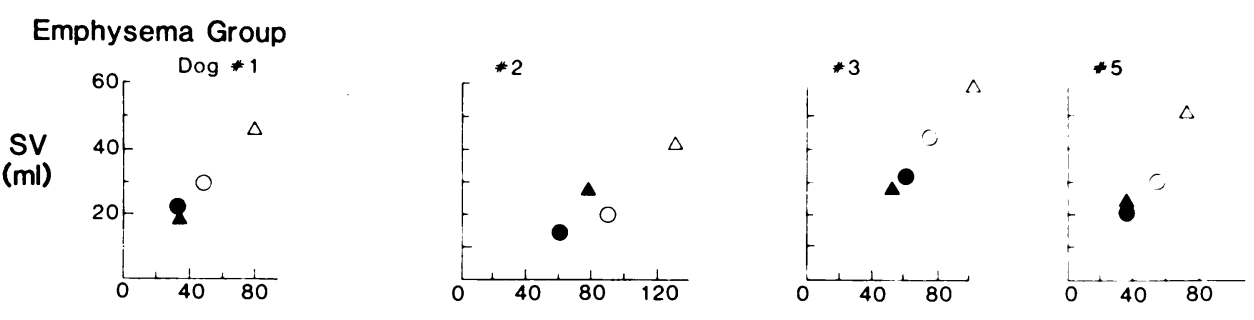

Control Group
SV
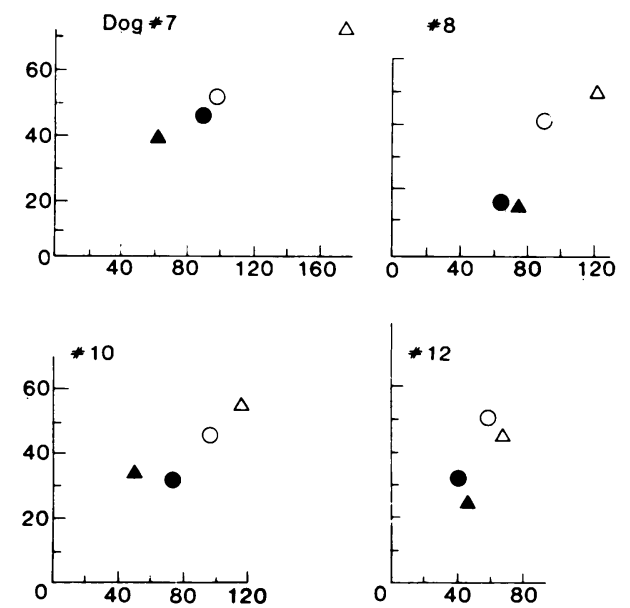
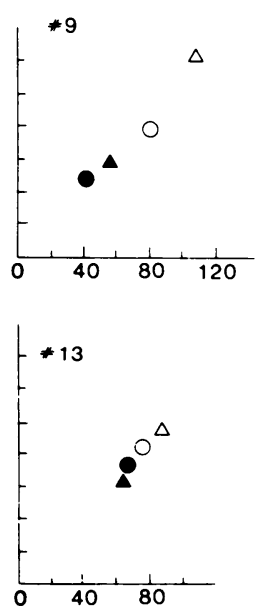

LVEDV

(ml)
Figure 5. SV is plotted on the ordinate against LVEDV on the abscissa for those dogs in the emphysema (dogs 1-3,5) and control groups (dogs 7-10, 12-13) for which both studies were completed (for dog 11, complete data were not obtained because of gamma camera failure during the hypoxic study). In the figure, triangles are used to indicate room air breathing; circles are used to indicate the hypoxic conditions. The open symbols represent the results obtained in the volume-loaded condition (i.e., V or VH); the solid symbols represent the results obtained before volume was given (i.e., $\mathrm{H}$ or $B_{2}$ ). All conditions considered, the coordinates appear to describe a single linear relationship and thus a single Frank-Starling relationship for most dogs. This finding would suggest that the relative reduction in SV in the volumeloaded hypoxic condition could be explained by a corresponding reduction in left ventricular filling volume. 
Table II. Indexes of Ventricular Systolic Performance in the Two Groups

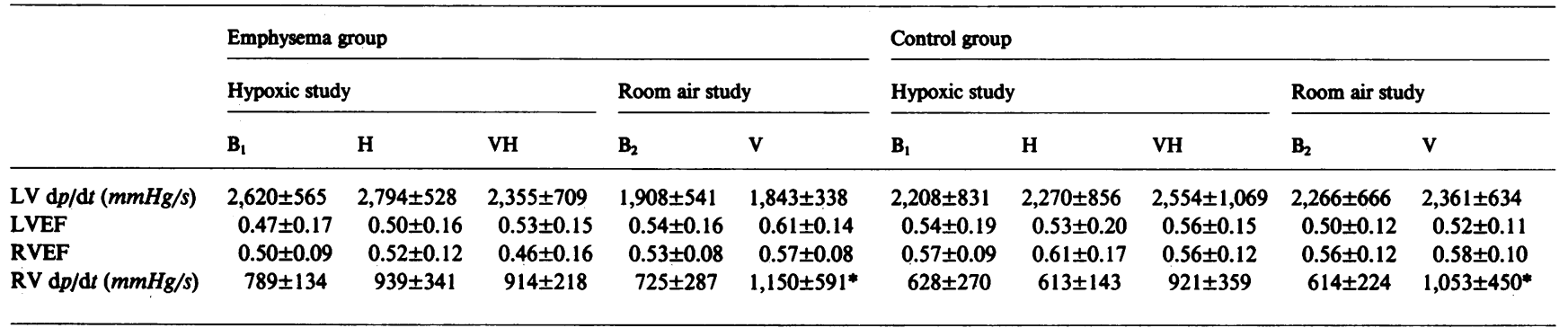

Values are given as mean $+\mathrm{SD}$. LV and RV dp/d $t$ are the maximal rates of rise of left and right ventricular pressures (mmHg/s), respectively; $\mathrm{LVEF}$ and $\mathrm{RVEF}$ are the ejection fractions of the left and right ventricles, respectively. $\mathrm{B}_{2}$ and $\mathrm{V}$ were obtained on room air breathing (room air study) before and after volume loading, respectively ( $n=7$ in the control group, $n=4$ in the emphysema group). $\mathrm{B}_{1}, \mathrm{H}$, and VH were obtained at the hypoxic study. H and VH were obtained on a hypoxic gas mixture $\mathrm{H}$ before and after volume loading, respectively ( $n=7$ in the control group; $n=6$ in the emphysema group). $* P<0.05$ from the preceding condition.

\section{Emphysema Group}

Hypoxic Study

Room Air Study

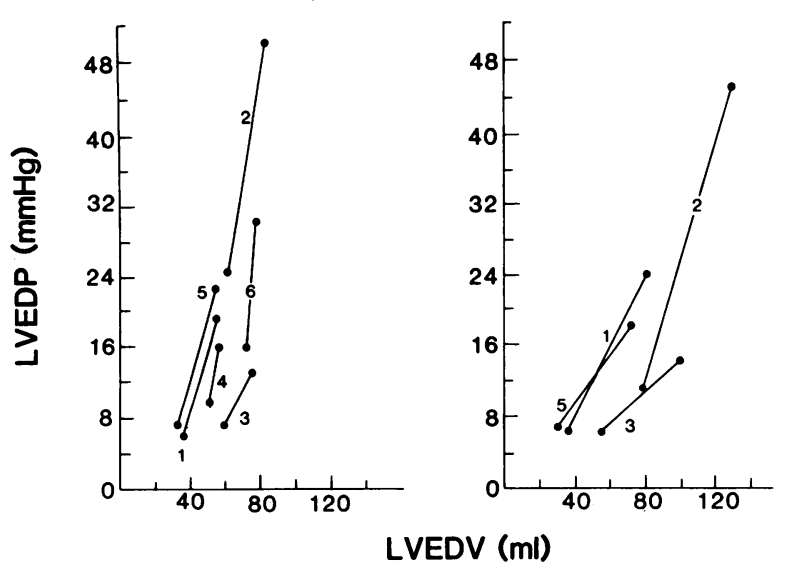

Control Group
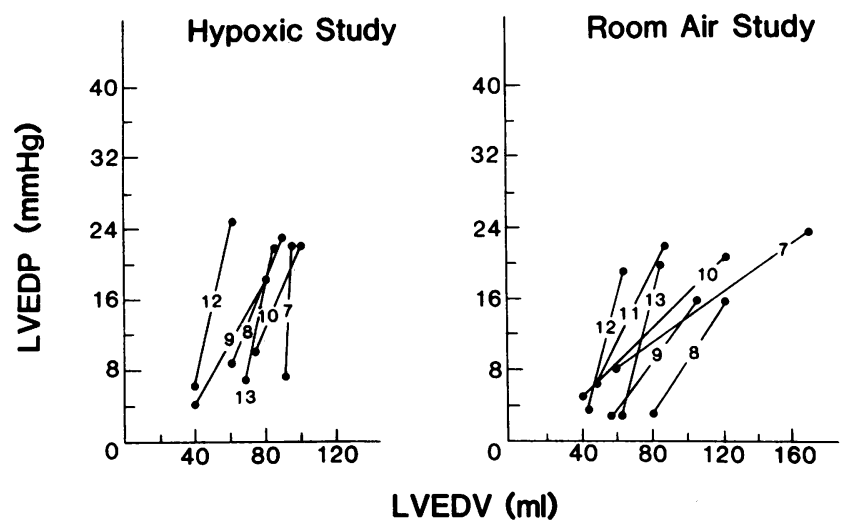

Figure 6. LVEDP is plotted on the ordinate against LVEDV on the abscissa for the individual dogs in the emphysema (dogs 1-6) and control (dogs 7-13) groups. Results were obtained at low and high levels of intravascular hydration on room air breathing $\left(B_{2}, V\right)$ and on a hypoxic gas mixture (H, VH). During the hypoxic study, the relationship of LVEDP to LVEDV for the individual dogs in both groups was shifted upward and to the left compared with the room air study. Diastolic elastance (1/compliance) during the hypoxic study was about twice that during the room air study in both groups (see text for details). This change in elastance resulted in a reduced LVEDV with volume expansion during hypoxia (see text for details). (Dog 11 results were not obtained during the hypoxic study because of gamma camera failure.) during the hypoxic study. In the emphysema group, diastolic elastance ( $\triangle$ LVEDP/ $\triangle$ LVEDV; mean \pm SD) increased from $0.39 \pm 0.20 \mathrm{mmHg} / \mathrm{ml}$ during the room air study to $0.75 \pm 0.3$ $\mathrm{mmHg} / \mathrm{ml}$ during the hypoxic study. In the control group, the increase was from $0.39 \pm .27$ to $1.17 \pm 1.04 \mathrm{mmHg} / \mathrm{ml}(P<0.025$ hypoxic study vs. room air study by paired $t$ test analyzed as described for Fig. $4 ; n=10$ ).

Mechanism of altered diastolic performance. The increased diastolic elastance (i.e., stiffness) of the left ventricle during the hypoxic study was investigated to determine whether it could be explained in terms of ventricular interdependence. If this were true, then increased diastolic filling of the right ventricle during hypoxia would result in a leftward shift in the septum. As shown in Table I, the RVEDV obtained during the volumeloaded hypoxic condition was not greater than during the volume-loaded room air condition in either group, but was slightly smaller during hypoxia. In the emphysema group, the decrease was from 92 to $80 \mathrm{ml}$, whereas in the control group the decrease was from 99 to $84 \mathrm{ml}$. Right ventricular systolic function assessed by $\mathrm{d} p / \mathrm{d} t$ was also well maintained during the hypoxic study (see Table II).

The relaxation variables are shown in Table III. The results indicate that alterations in left ventricular relaxation occurred during the hypoxic study which may have contributed to the decrease in diastolic compliance in that study. There were no differences between the two groups, and when the volume loaded conditions were compared, the time constant of ventricular relaxation calculated by Weiss et al. (10) increased significantly during hypoxia. There was also a significant increase in this time constant after volume administration during hypoxia (i.e., from $\mathrm{H}$ to $\mathrm{VH})$. The time constant of ventricular relaxation determined by Raff et al. (14) increased only marginally between the two volume-loaded conditions. In the volume-loaded condition, $P b$ was more positive during hypoxia, but there was some overlap between the hypoxic and room air conditions. $P b$ may characterize the extent of relaxation rather than the rate (14), and the tendency for this parameter to increase during hypoxia is consistent with increased myocardial stiffness during that study (see Discussion).

\section{Ultrasonic Sonomicrometry Studies}

Ultrasonic sonomicrometry was used in six acute canine experiments to measure end-diastolic and end-systolic dimensions of the left ventricle during hypoxia and room air breathing. The results obtained in the crystal study corroborated the radionuclide angiography findings. $\overline{\text { Pwp }}$ averaged $( \pm \mathrm{SD}) 12 \pm 3.7 \mathrm{mmHg}$ dur- 


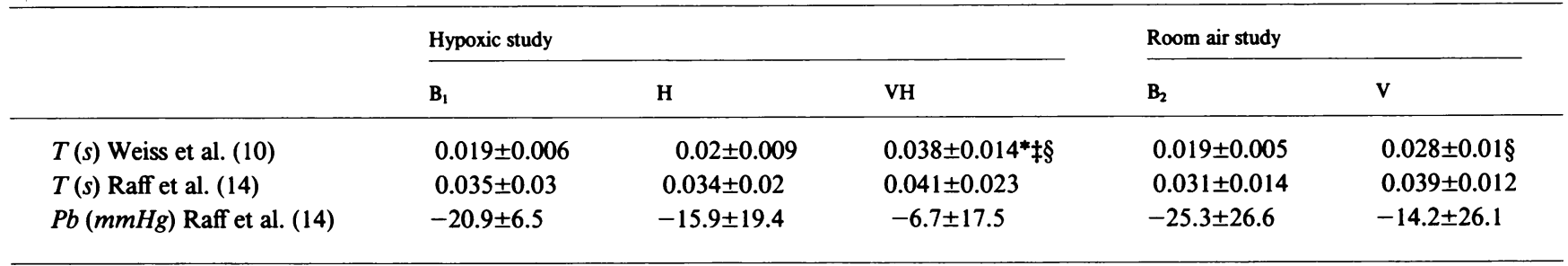

Data represent mean \pm SD of all dogs in which all conditions were present (seven dogs in the control group and four dogs in the emphysema group). There were no differences between the two groups. Analyzed by two-way ANOVA and Tukey's multiple comparison test. $T(s)$ is the time constant calculated from the isovolumic pressure fall of the left ventricle described in the respective studies. $\mathrm{Pb}(\mathrm{mmHg})$ is the modeling constant described by Raff et al. (14). ${ }^{*}$ VH vs. V $P<0.05$. $\ddagger$ VH vs. H $P<0.05$. $\S \mathrm{B}_{1}+\mathrm{B}_{2}$ vs. VH + V, respectively $P<0.01$.

ing the hypoxic condition and $12 \pm 3.8 \mathrm{mmHg}$ during the room air condition, while $\overline{R a p}$ averaged $( \pm \mathrm{SD}) 3.6 \pm 1$ and $4.3 \pm 1.7$ $\mathrm{mmHg}$, respectively. An example of the left ventricular diameter tracings obtained during hypoxic and room air conditions is shown in Fig. 7; the mean results are shown in Table IV. Endsystolic dimensions remained unchanged during the two conditions indicating that the systolic performance of the left ventricle was unchanged at a $\mathrm{PO}_{2}$ of $35 \mathrm{mmHg}$. On the other hand, the end-diastolic dimensions decreased during hypoxia along all axes, particularly the apex to base and the septal to lateral free wall. A relative decrease in end-diastolic dimensions during hypoxia indicates that the stiffness of the left ventricle increased and agrees with the radionuclide angiography data. In the left ventricular sonomicrometry study, the mean right atrial pressures (mean \pm SD) obtained during hypoxia $(3.6 \pm 1 \mathrm{mmHg}$ ) and room air $(4.3 \pm 1.7 \mathrm{mmHg})$ were about the same. The lack of an increase in right atrial pressure during hypoxia would argue against right ventricular enlargement and hence a shift in the septum from right to left as an explanation for the decrease in left ventricular compliance during this condition.

The right ventricular sonomicrometry study showed that the right ventricular free wall to septal end-diastolic dimension also

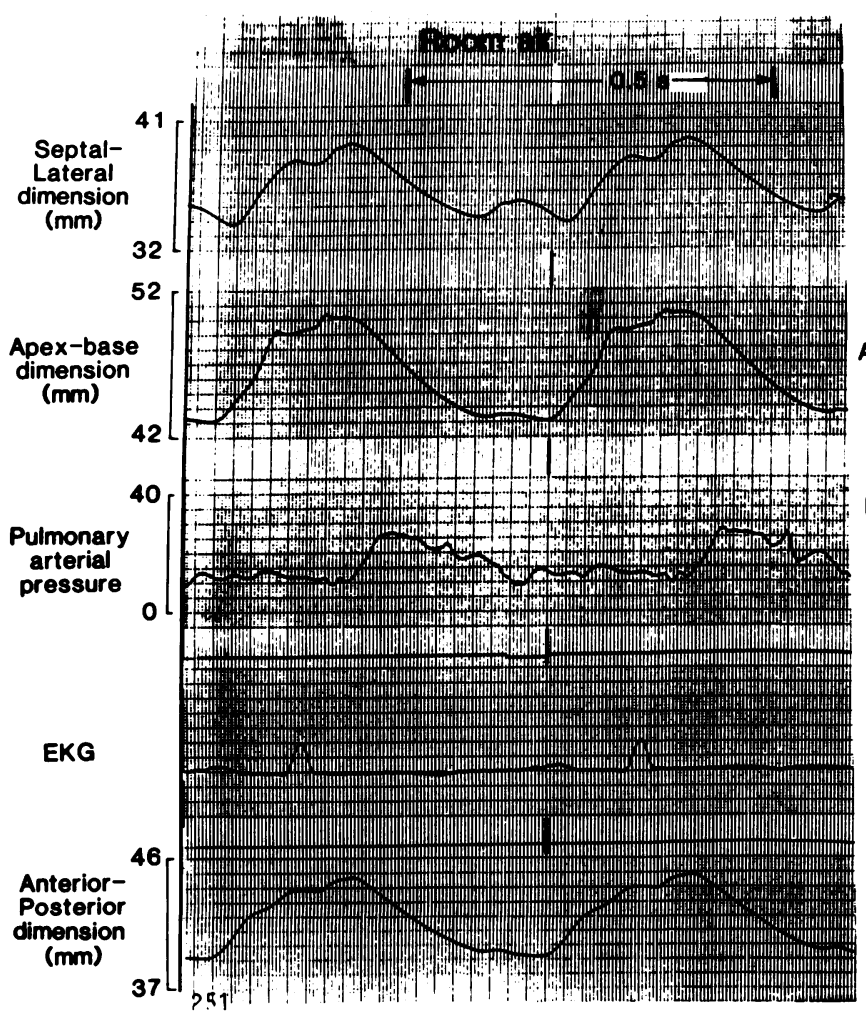

Figure 7. In this example, the absolute distance between transducer pairs (ultrasonic crystals) is shown for three dimensions of the left ventricle. Room air (left) and hypoxic conditions (right) are shown. The greatest distance between the ultrasonic crystals represents the end-diastolic diameter, whereas the smallest distance between the ultrasonic crystals represents the end-systolic diameter. For identical wedge pressures in the two conditions, end-diastolic dimensions were smaller

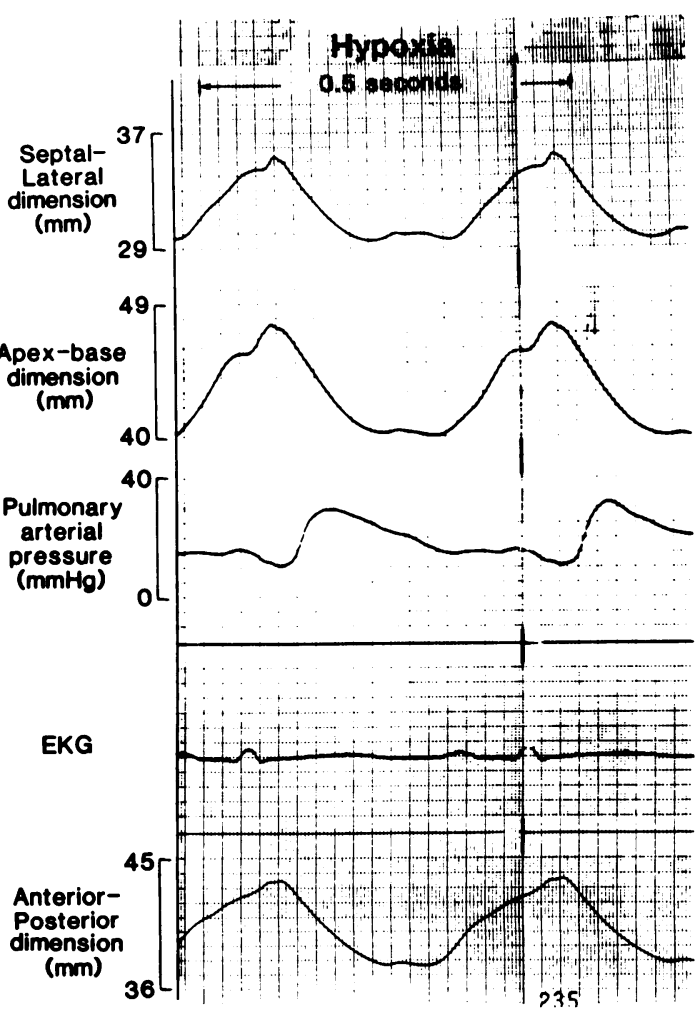

during the hypoxic condition along all axes. This finding would indicate an increase in diastolic stiffness of the left ventricle during hypoxia (note the scale change between the two conditions which would tend to underestimate the differences). End-systolic dimensions, however, remained the same during the two conditions, a finding that would indicate that systolic performance was unchanged (see text for details; see Robotham et al. [28] for crystal positioning). 
Table IV. End-systolic and End-diastolic Dimensions of the Left Ventricle during Hypoxic and Room Air Volume-loaded Conditions Measured by Sonomicrometry in an Acute Canine Experiment

\begin{tabular}{lll}
\hline & $\begin{array}{l}\text { Room air } \\
\text { (V) }\end{array}$ & $\begin{array}{l}\text { Hypoxia } \\
\text { (VH) }\end{array}$ \\
\hline & $m m$ & $m m$ \\
Septal-lateral dimension $(n=4)$ & & \\
$\quad$ End diastole & $30.4 \pm 7.95$ & $26.8 \pm 8.6^{*}$ \\
$\quad$ End systole & $25.3 \pm 7.95$ & $23.2 \pm 7.3$ \\
$\begin{array}{l}\text { Apex-base dimension }(n=6) \\
\quad \text { End diastole }\end{array}$ & $56.1 \pm 4.8$ & $53.2 \pm 5^{*}$ \\
$\quad$ End systole & $48.5 \pm 5.5$ & $48.6 \pm 6$ \\
Anterior-posterior dimension $(n=6)$ & & \\
$\quad$ End diastole & $43.6 \pm 2.3$ & $42.6 \pm 2.2^{*}$ \\
$\quad$ End systole & $38.1 \pm 3.8$ & $38.2 \pm 3.1$ \\
& & \\
& &
\end{tabular}

All values are given as mean $\pm \mathrm{SD}$.

$* P<0.01 \mathrm{VH}$ vs. V paired $t$ test.

decreased during hypoxia indicating that the effect of hypoxia on ventricular diastolic compliance was a global one. The enddiastolic dimension decreased from (mean \pm SD) $16.5 \pm 8.4 \mathrm{~mm}$ during room air to $14.9 \pm 8.8 \mathrm{~mm}(P<0.05$; paired $t$ test $)$ during hypoxia, while end-systolic dimensions remained unchanged (10.2 $\pm 6.9 \mathrm{~mm}$ during room air vs. 10.0 \pm 7.2 during hypoxia). $\overline{\mathrm{Rap}}$ and $\overline{\mathrm{Pwp}}$ (room air vs. hypoxia; mean \pm SD) were $6.5 \pm 1.7$ vs. $6.6 \pm 2 \mathrm{mmHg}$ and $13.5 \pm 4$ vs. $14.2 \pm 5 \mathrm{mmHg}$, respectively. In Fig. 8, the right ventricular end-diastolic dimension is shown to decrease during the first few minutes of hypoxia, though right atrial pressure remains the same.

\section{Discussion}

Left ventricular mechanics were examined in a canine model of pulmonary emphysema in which measurements were obtained during severe hypoxemia similar to that which may occur during respiratory failure. This study is the first to consider that abnormalities in ventricular relaxation might be important during an acute exacerbation of COPD. In the emphysema group, a severe lesion was produced. Total lung capacity was increased by $60 \%$ relative to the pre-papain value, and mean pulmonary artery pressure was elevated to a level comparable to that observed in human disease (29).

We administered a low-oxygen-concentration gas mixture to the control and emphysema groups during the hypoxic study to produce the severe reductions in alveolar and arterial oxygen tensions that would occur during respiratory failure when worsening oxygen transfer in diseased lungs would lead to tissue hypoxia. By including both control and emphysema groups in our study, we could examine whether the changes in ventricular performance during respiratory failure were due to the effect of decreased oxygen transfer (i.e., hypoxic hypoxia) alone in the control group or related to the combined effects of decreased oxygen transfer and the hemodynamic and lung function changes of emphysema in the papain-treated group. During acute hypoxemia, left ventricular performance may be affected differently in the two groups because of the reduced pulmonary capillary bed and slightly increased right ventricular afterload caused by emphysema (5-8, 20, 22).

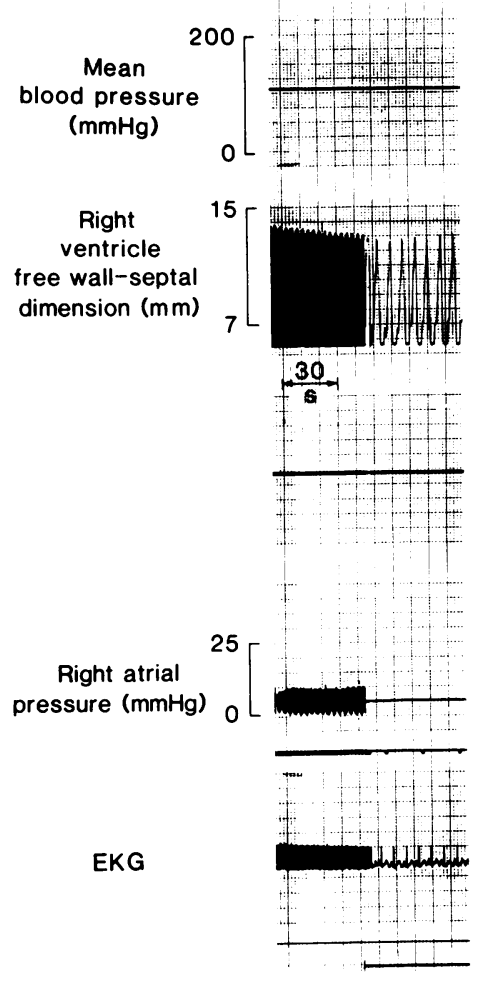

Figure 8. Septal to free wall dimension of the right ventricle is shown (see text for crystal positioning). After $\sim 1$ min of hypoxia, the end-diastolic dimension is shown to decrease while right atrial pressure remained unchanged (mean right atrial pressure is shown after the 30 -s interval). Because the end-diastolic dimension decreased, a shift of the septum from right to left was not responsible for the decrease in left ventricular compliance during hypoxia. End-systolic dimension remains unchanged indicating that the systolic performance of right ventricle was maintained.

The results of the study showed that left ventricular diastolic compliance was decreased in both the control and emphysema groups during hypoxia, while systolic performance remained unchanged. The decrease in left ventricular diastolic compliance was most apparent in the volume-loaded condition when during hypoxia a decrease in LVEDV resulted in a smaller SV. There was no difference, however, between dogs with and without emphysema in terms of hypoxia-induced changes in ventricular performance. Thus, it was the effect of hypoxic hypoxia alone that resulted in the decrease in left ventricular diastolic compliance, and the pulmonary hypertension and lung function changes owing to emphysema had little, if any, additional effect. The latter findings are consistent with our previous study in which left ventricular performance was unchanged in dogs with pulmonary hypertension due to emphysema examined while breathing room air to mimic the stable COPD condition (20). In terms of the present study, therefore, severely reduced oxygen transfer in emphysematous lungs is the pathologic basis for a decrease in left ventricular diastolic compliance during respiratory failure. In turn, this gas exchange abnormality could bring about diastolic impairment by the mechanisms described below.

The hypoxia-induced changes in ventricular performance occurred whether the dogs in the emphysema and control groups were randomized to have the hypoxic study performed before or after the room air study. Thus, the mechanism causing the decrease in left ventricular diastolic compliance during hypoxic hypoxia was reversible. We considered two possible mechanisms that could cause such a reversible increase in left ventricular stiffness. One included the effects of ventricular interaction and the pericardium on limiting left ventricular filling (2-8) and the other was the effect of reduced oxygen delivery on altering the diastolic properties of the left ventricle through mechanisms that may be indicative of altered ventricular relaxation (see below; 9-15). 
In terms of ventricular interaction, during the hypoxic study, pulmonary vasconstriction owing to reduced alveolar and pulmonary arterial oxygen tensions may have increased right ventricular afterload and end-diastolic volume leading to a leftward shift in the interventricular septum and to a decrease in left ventricular diastolic compliance $(2-7,30,31)$. Taylor et al. (3) showed that the left ventricular pressure-volume curve depended on right ventricular volume. As right ventricular volume and pressure increased, the left ventricular pressure-volume curve shifted leftward and steepened, a finding which would indicate a decrease in compliance. The pericardium also contributes to the mechanical behavior of the ventricles $(6,8)$ by restricting the expansion of the entire heart and increasing the extent to which one side of the heart affects the other.

In the emphysema and control groups, we found that relative to the room air condition, right ventricular end-diastolic volume (see Table I) was slightly smaller in the volume-loaded hypoxic condition. In the absence of an increase in right ventricular volume, left ventricular diastolic compliance should not decrease by ventricular interdependence. Indeed, to further substantiate that ventricular interaction did not account for the decrease in diastolic compliance in the emphysema study, additional experiments were performed in which piezoelectric crystals were used to measure diastolic and systolic changes (see Results subsection "Ultrasonic sonomicrometry studies"). Left ventricular end-diastolic dimensions decreased during hypoxia. This decrease occurred despite the fact that the pericardium was removed, when the effect of right ventricular enlargement on left ventricular diastolic compliance would be minimized (8), and even though $\overline{\operatorname{Rap}}$ was slightly lower during hypoxia than during room air breathing. The latter finding would argue that right ventricular end-diastolic volume was, if anything, smaller during the hypoxic condition. Moreover, that a septal shift from right to left was not responsible for the decrease in left ventricular diastolic compliance during hypoxia was further supported by the crystal results obtained from the right ventricular study. The free wall to septal end-diastolic dimension of the right ventricle also decreased during hypoxia, indicating that hypoxia affects the diastolic compliance of both ventricles.

We conclude therefore that hypoxia directly altered the diastolic properties of the left ventricle in both the emphysema and crystal studies. In terms of Serizawa et al. (13), the increased myocardial stiffness observed during hypoxia may be indicative of incomplete or partial ventricular relaxation (see below). Ventricular relaxation has been shown to be a dynamic, energy dependent process $(9,12,13,32-34)$. When the energy supply to the heart muscle is decreased, the relaxation process may be altered such that increased ventricular resting tone occurs for a given end diastolic volume. The normal relaxation process of cardiac muscle predominantly relies on active sequestration of calcium by the sarcoplasmic reticulum to reverse the interaction of the contracting proteins $(13,33-36)$. Serizawa et al. (13) have previously shown in isolated hearts that anoxic $\left(\mathrm{PO}_{2}<10 \mathrm{mmHg}\right)$ conditions increased ventricular diastolic pressure relative to volume throughout diastole. This increase in pressure occurred within minutes of anoxia, was reversible, and was related to myocardial oxygen supply-demand imbalance. In Table III of Serizawa et al. (13), hypoxia increased LVEDP for a given enddiastolic volume from 10 to $20 \mathrm{mmHg}$ with heart rate held constant at 120 beats/min. After myocardial oxygen supply-demand imbalance was further increased after tachycardia, there was an additional increase in LVEDP to $24 \mathrm{mmHg}$.
Moreover, Serizawa et al. distinguish between two abnormalities of ventricular relaxation: the rate of ventricular relaxation and the extent to which it occurs. These abnormalities may represent two independent aspects of the relaxation process. The rate of ventricular relaxation is determined by the time constant of relaxation described by Weiss et al. (10). If the time constant were sufficiently prolonged during hypoxic conditions, then systole could occur before a previous diastole was completed. The biochemical abnormality proposed for an increased time constant is a decreased rate of removal of calcium from the cytosol by the sarcoplasmic reticulum brought about by reduced energy supply. On the other hand, anoxia may cause an increase of the elastance of resting muscle so that ventricular volume is reduced for a given filling pressure (i.e., a reduction in the extent of relaxation), even if the increase in the time constant of isovolumic relaxation were small. Such a decrease in ventricular distensibility is referred to as incomplete ventricular relaxation $(12,13,34-36)$ and would lead to a decrease in myocardial distensibility throughout diastole, even at slow heart rates. The fundamental mechanisms responsible for this decrease in distensibility and thus the persistent contractile interaction of actin and myosin filaments throughout diastole are not clear. Possibilities include ATP deficiency, cytosolic calcium overload, or increased sensitivity of the contractile proteins to a given concentration of diastolic calcium (34-36).

Within the framework of Serizawa et al. (13), the major effect of hypoxia in the present experiment was to cause a reduction in the extent of myocardial relaxation for a given pressure, and this finding would reflect incomplete ventricular relaxation. A decreased rate of ventricular relaxation appeared not to be the mechanism. Weisfeldt et al. (11) showed that an increased time constant of isovolumic relaxation would not lead to increased end-diastolic pressures if the next beat began $>3.5$ time constants after minimum $\mathrm{d} p / \mathrm{d} t$. In the present study, the increase in the time constant of isovolumic ventricular relaxation between the volume-loaded hypoxic and room air conditions $(\sim 10 \mathrm{~ms}$ as determined by Weiss et al. (10); see Table III) was relatively small considering the length of diastole (i.e., $250 \mathrm{~ms}$ ). Because $>3.5$ time constants passed between beats during all conditions, a decreased rate of relaxation did not cause the change in diastolic compliance during hypoxia. Thus, diastolic compliance was reduced during hypoxia because of incomplete ventricular relaxation, a process which may reflect increased interaction of the contractile proteins thoughout diastole (13). Importantly, however, there is no specific measurement to test that incomplete ventricular relaxation was the mechanism, and our conclusions were reached after ruling out the major other possibility, ventricular interdependence (2-8). We are aware therefore that in interpreting our results the data only convincingly show that the ventricle became stiffer during hypoxia and acknowledge the limitation of our conclusion that incomplete ventricular relaxation was the mechanism.

With respect to the present findings, however, recent studies utilizing a canine model of angina (34-36) would indeed indicate that a reduction in the extent of ventricular relaxation may lead to increased myocardial stiffness, even if the time constant of isovolumic relaxation were not appreciably increased. In dogs with coronary stenoses, Paulus et al. (35) examined the changes in left ventricular diastolic properties after the administration of caffeine, an agent which by increasing intracellular myocardial calcium availability may potentiate relaxation abnormalities. Myocardial oxygen demand was increased in that study by in- 
creasing heart rate (by pacing tachycardia), and measurements were obtained immediately after pacing before and after the drug was administered. The time constant of isovolumic ventricular relaxation obtained after pacing did not change with caffeine ( $52 \mathrm{~ms}$ both before and after), yet increased myocardial stiffness occurred with the drug. For similar ventricular dimensions with and without caffeine, LVEDP increased after caffeine from 15 to $27 \mathrm{mmHg}$. The heart rates obtained after pacing were similar with and without caffeine, 122 vs. 129 beats/min, respectively. Thus, caffeine increased ventricular diastolic stiffness after pacing, a finding that was ascribed to incomplete relaxation and was observed without an increase in the time constant of isovolumic relaxation. Moreover, Momomura et al. (34) and Paulus et al. (36) examined the effect of tachycardia alone on diastolic distensibility in dogs with coronary stenoses. Compared with the condition before pacing, the increase in the time constant of isovolumic relaxation was small after pacing in both studies and was similar to that found in the present study (before vs. after pacing: 37 vs. $47 \mathrm{~ms}$ in Momomura et al. [34]; and 34 vs. $53 \mathrm{~ms}$ in Paulus et al. [35]). Yet, in both angina studies, left ventricular diastolic pressure-segment relations were shifted upward and to the left after pacing. In the study of Paulus et al. (36), left ventricular material properties were also assessed, and the left ventricular radial elastic modulus increased after pacing. Further, in isolated hearts, Weisfeldt et al. (12) found that during anoxic conditions, end-diastolic pressure was increased relative to volume, although the rate of pressure decay was not decreased (see their Table II). Thus, a reduction in diastolic compliance attributable to incomplete ventricular relaxation may be observed when the time constant of isovolumic ventricular relaxation is not substantially increased.

The present study indicates that hypoxia-induced decreases in diastolic compliance may be an important mechanism of impaired left ventricular diastolic performance during an acute exacerbation of COPD. In acute respiratory failure, because of a low arterial $\mathrm{PO}_{2}$, myocardial oxygen demand would exceed supply and left ventricular pressure distensibility would be decreased. Since end-diastolic volume would be relatively reduced for a given end-diastolic pressure, a decrease in SV would occur. Although a compensatory increase in end-diastolic volume could restore SV, pulmonary microvascular pressure might rise high enough to cause pulmonary edema. Other investigators have examined relaxation mechanics using isolated heart preparations in which oxygen delivery to the heart muscle was zero $(12,13)$ and thus a level of $\mathrm{PO}_{2}$ compatible with life for only a few minutes. We used a whole-animal preparation with levels of $\mathrm{PO}_{2}$ similar to those observed during human respiratory failure. Like many humans, the animals made a complete recovery after about one hour of severe hypoxia. Our results suggest therefore that the hypoxemia that occurs during respiratory failure is sufficient to cause a decrease in diastolic compliance and that this diastolic impairment is reversible.

Our results indicate, moreover, that diastolic impairment of the left ventricle occurred without systolic impairment. Possibly circulating catecholamines maintained systolic function to a greater extent than diastolic function. Alternatively systolic performance is less sensitive to hypoxia than diastolic performance. There is support for both mechanisms in the literature. As previously mentioned, Paulus et al. (36) examined the effect of caffeine, a positive inotropic agent, on left ventricular hemodynamics after pacing in dogs with coronary stenoses. After tachycardia, caffeine shifted the left ventricular diastolic pressuresegment relations upward and to the left compared with the results obtained without the drug, while systolic performance tended to improve. Thus diastolic impairment occurred without systolic impairment, findings identical to those observed in the present study. In the study of Paulus et al. (36), the decrease in left ventricular diastolic compliance could be due to caffeine's effect on myocardial cellular calcium metabolism, whereas the improved systolic performance could be related to its inotropic effect. In another study, Bing et al. (37) showed that isoproterenol improved systolic function in isolated rat trabecular muscle subjected to hypoxia, while it hastened the appearance of relaxation abnormalities because of increased substrate utilization.

On the other hand, Brutsaert et al. (38) indicated that load dependence of relaxation of cardiac muscle is suppressed during hypoxia and is observed even before systolic force falls. Serizawa et al. (13) correlated myocardial lactate levels with abnormalities in ventricular relaxation in an isolated heart preparation. In two of their experiments, in which the heart was perfused with a solution equilibrated with $95 \%$ oxygen, $5 \% \mathrm{CO}_{2}$ (their Fig. 3), diastolic pressure increased during tachycardia, whereas systolic pressure, rather than decreasing, remained relatively unchanged. After cessation of tachycardia, the increase in left ventricular diastolic pressure persisted for $\sim 30 \mathrm{~s}$. In those experiments, therefore, diastolic impairment occurred without systolic impairment and the authors comment that lactate accumulation in those experiments was particularly high. Moreover, in another experiment in Serizawa et al. (13; Fig. 4 bottom) in which diastolic and systolic pressures were observed after the heart was perfused with a solution equilibrated with $95 \%$ nitrogen, $5 \% \mathrm{CO}_{2}$, an increase in diastolic pressure occurred much earlier than a decrease in systolic pressure. In $\beta$-adrenergic blocked dogs with coronary stenoses, Paulus et al. (36) indicated that diastolic dysfunction was most pronounced after tachycardia in those animals in which systolic function was well preserved. Thus, previous studies have indicated a dissociation between ventricular systolic and diastolic changes. In terms of the present study, at a $\mathrm{PO}_{2}$ of $35 \mathrm{mmHg}$, oxygen delivery was sufficient to maintain systolic performance, while diastolic performance was impaired. Whether there is a different threshold for each is not clear. Because the mechanism of the decrease in diastolic compliance during hypoxia is not known, the subcellar events that would account for the divergent systolic and diastolic effects become difficult to assess. Importantly, however, our results show that in the condition of respiratory failure, diastolic impairment may occur before systolic impairment.

We designed the emphysema experiment so that the only variable that would change between the hypoxic and room air studies was $\mathrm{PO}_{2}$. Parameters were also measured over a short time period $(0.5-1.0 \mathrm{~h})$. Concomitant changes in $\mathrm{PCO}_{2}$ and $\mathrm{pH}$ or a longer time period under hypoxic conditions might alter cardiac parameters in a different manner. We recognize that the study must be interpreted in the context of the anesthesia used and the emphysema model produced (i.e., pink puffer type). The $10-\mathrm{mmHg}$ increase in pulmonary artery pressure produced in the model did not alter the spatial interaction of the right and left ventricles, since there was no difference in the hemodynamic findings between the emphysema and control groups in the two studies. Greater increases in pulmonary artery pressure owing to emphysema may have produced differences in left ventricular performance between the two groups. Coronary perfusion pressure also exerts an independent effect on ventricular resting tension and has an "erectile" effect on the myocardium $(16,39)$. For a given ventricular volume, as coronary perfusion pressure decreases, end-diastolic pressure falls and vice versa. Coronary 
perfusion pressure as determined by mean systemic blood pressure did not change between the hypoxic and room air studies (see Fig. 2), nor did heart rate which may also have an independent effect on relaxation properties (10, see Table I). Further, measurements were obtained at functional residual capacity to avoid the consideration of respiratory effects on ventricular function.

Glantz and Parmley (2) did not consider that hypoxia was a factor in altering diastolic compliance in their review article on this subject. However, their paper antedated the work of Serizawa et al. (13) who considered the rate of ventricular relaxation as well as the extent of relaxation important in the analysis of hypoxia-induced diastolic effects. The review article also preceded the work of Frist et al. (9) who showed that in isolated cat papillary muscle maintained at $38^{\circ} \mathrm{C}$, relaxation time was increased rather than decreased during hypoxic conditions. Frist et al. (9) pointed out that because conditions were maintained hypothermic in previous studies of hypoxic papillary muscle, a decreased rate of relaxation was not observed.

In summary, our results showed that hypoxic hypoxia decreased the diastolic compliance of the left ventricle in dogs with pulmonary emphysema. This decrease appeared to be an effect of hypoxia per se on the left ventricle and to reflect incomplete ventricular relaxation. Right ventricular enlargement did not occur between the hypoxic and room air volume-loaded conditions to explain the reduction in compliance in terms of ventricular interdependence theory. In terms of our study, severely reduced oxygen transfer in emphysematous lungs during respiratory decompensation would lead to myocardial hypoxia and cause diastolic impairment. Accompanying hemodynamic and lung function changes of emphysema would contribute little to this effect. Diastolic impairment because of a direct effect of hypoxia has not been described in the context of an acute on chronic respiratory failure, and our results show that the hypoxemia that occurs in this setting is sufficient to induce this effect. The results further show that the decrease in diastolic performance during hypoxia is reversible and may occur before systolic dysfunction is observed. Because a decrease in ventricular diastolic compliance leads to a reduction in ventricular filling, cardiac output reduction may result during respiratory decompensation.

Further, our results do not lessen the significance of ventricular interaction as also playing an important role during respiratory decompensation. Human subjects may show a greater degree of hypoxic pulmonary vasoconstriction than do dogs (particularly since pulmonary hypoxic vasoconstriction in dogs is attenuated at the high pulmonary vascular venous pressures used in the present study [30]). A large increase in right ventricular afterload would increase the extent to which right ventricular enlargement and hence ventricular interaction occurred. In the present experiment, the effect of hypoxia on reducing RVEDV was greater than the effect of pulmonary hypoxic vasoconstriction on increasing it; the net result was that RVEDV decreased. Under other circumstances, the importance of ventricular interaction as a cause for decreased left ventricular compliance during respiratory decompensation might differ, but it is probable that if hypoxemia is severe, a direct effect of hypoxia on increasing myocardial stiffness is also important.

\section{Acknowledgments}

The authors wish to thank Dr. N. R. Anthonisen for his critical review of the manuscript, Dr. D. Greenberg and G. Woods for their help in obtaining the radionuclear measurements, K. Duke and J. Eng for their technical assistance, and $\mathrm{K}$. Brad for her secretarial assistance.

This study was supported by the Canadian Heart Foundation and the Texas Heart Affiliate of the American Heart Association. Dr. Mink is a scholar of the Manitoba Health Research Council; Dr. Gomez is a fellow of the Health Service of Mexico.

\section{References}

1. Tyberg, J. V., Y. A. Yeatman, W. W. Parmley, C. W. Urschel, and E. H. Sonnenblick. 1970. Effects of hypoxia on mechanics of cardiac contraction. Am. J. Physiol. 218:1780-1788.

2. Glantz, S. A., and W. W. Parmley. 1978. Factors which affect the diastolic-pressure volume curve. Circ. Res. 42:171-180.

3. Taylor, R. R., J. W. Covell, E. H. Sonnenblick, and J. Ross. 1967. Dependence of ventricular distensibility on filling of the opposite ventricle. Am. J. Physiol. 213:711-718.

4. Laks, M. M., D. Garner, and H. J. C. Swan. 1967. Volumes and compliances measured simultaneously in the right and left ventricles of the dog. Circ. Res. 20:565-569.

5. Jardin, F., P. Gueret, J. Prost, J. Farcot, Y. Ozier, and J. Bourdarias. 1983. Two-dimensional echocardiographic assessment of left ventricular function in chronic obstructive pulmonary disease. Am. Rev. Respir. Dis. 129:129-142.

6. Glantz, S. A., G. A. Misbach, W. Y. Moores, D. G. Mathey, J. LeKven, D. F. Stowe, W. W. Parmley, and J. V. Tyberg. 1978. The pericardium substantially affects the left ventricular pressure-volume relationship in the dogs. Circ. Res. 42:422-441.

7. Weber, K., J. Janicki, S. Shroff, M. Likoff, and M. Sutton. 1983. The right ventricle: physiologic and pathophysiologic considerations. Crit. Care Med. 11:323-328.

8. Janicki, J., and K. Weber. 1980. The pericardium and ventricular interaction, distensibility, and function. Am. J. Physiol. 238 (Heart Circ. Physiol. 7):H494-H503.

9. Frist, W. H., I. Palacios, and W. J. Powell. 1978. Effect of hypoxia on myocardial relaxation in isometric papillary muscle. J. Clin. Invest. 61:1218-1224.

10. Weiss, J. L., J. W. Frederiksen, and M. Weisfeldt. 1976. Hemodynamic determinants of the time-course of fall in canine left ventricular pressure. J. Clin. Invest. 58:751-760.

11. Weisfeldt, M., J. W. Frederiksen, F. C. P. Yin, and J. L. Weiss. 1978. Evidence of incomplete left ventricular relaxation in the dog. $J$. Clin. Invest. 62:1296-1302.

12. Weisfeldt, M. L., P. Armstrong, H. E. Scully, C. A. Sanders, and W. M. Daggett. 1974. Incomplete relaxation between beats after myocardial hypoxia and ischemia. J. Clin. Invest. 53:1626-1636.

13. Serizawa, T., W. Vogel, C. Apstein, and W. Grossman. 1981. Comparison of acute alterations of left ventricular relaxation and diastolic chamber stiffness induced by hypoxia and ischemia. J. Clin. Invest. 68: 91-102.

14. Raff, G. L., and S. A. Glantz. 1981. Volume loading slows left ventricular isovolumic relaxation rate. Circ. Res. 48:813-824.

15. Katz, A. M., L. N. Katz, and F. L. Williams. 1955. Registration of left ventricular volume curves in the dogs with the systemic circulation intact. Circ. Res. 3:588-593.

16. Vogel, W. H., C. S. Apstein, L. L. Briggs, W. H. Gaasch, and J. Ahn. 1982. Acute alterations in left ventricular diastolic chamber stiffness. Circ. Res. 51:465-478.

17. Grossman, W., and W. Barry. 1980. Diastolic pressure-volume relations in the diseased heart. Fed. Proc. 39:148-155.

18. Barry, W. H., J. Brooker, E. L. Alderman, and D. C. Harrison. 1974. Changes in diastolic stiffness and tone of the left ventricle during angina pectoris. Circulation. 49:255-263.

19. Pushpakon, R., J. C. Hogg, A. J. Woolcock, A. E. Angus, P. T. Macklem, and W. M. Thurlbeck. 1970. Experimental papain-induced emphysema in dogs. Am. Rev. Respir. Dis. 102:778-779.

20. Mink, S. N., A. Gomez, L. Whitley, and J. Coalson. 1986. Hemodynamics in dogs with pulmonary hypertension due to emphysema. Lung. 164:41-54. 
21. Mink, S. N. 1984. Expiratory flow limitation and the response to breathing a helium-oxygen mixture in a canine model of pulmonary emphysema. J. Clin. Invest. 73:1321-1334.

22. Mink, S. N., H. H. Unruh, and L. Oppenheimer. 1985. Vascular and interstitial mechanics in canine pulmonary emphysema. J. Appl. Physiol. 59:1704-1715.

23. Mink, S. N., R. B. Light, and L. D. H. Wood. 1981. Effect of pneumococcal lobar pneumonia on canine lung mechanics. J. Appl. Physiol. (Respir. Environ. Exercise Physiol.) 50:524-530.

24. Cook, C. D., J. Mead, G. L. Schreiner, N. R. Frank, and J. M. Craig. 1969. Pulmonary mechanics during induced pulmonary edema in anesthetized dogs. J. Appl. Physiol. 14:177-186.

25. Swain, J. L., K. H. Morris, F. P. Bruno, and F. R. Cobb. 1980. Comparison of multigated radionuclide angiography with ultrasonic sonomicrometry over a wide range of ventricular function in conscious dog. Am. J. Cardiol. 46:976-982.

26. Sodums, M. T., F. R. Badke, M. R. Starling, W. C. Little, and R. A. O'Rourke. 1984. Evaluation of left ventricular contractile performance utilizing end-systolic pressure-volume relationships in conscious dogs. Circ. Res. 54:731-739.

27. Kay, H. R., A. Manoucher, P. Barash, W. Webler, A. Iskandrian, C. Bemis, A. Hakki, and E. Mundth. 1983. Measurement of ejection fraction by thermal dilution techniques. J. Surg. Res. 34:337-346.

28. Robotham, J. L., F. R. Badke, M. K. Kindred, and M. K. Beaton. 1983. Regional ventricular performance during normal and obstructed spontaneous respiration. J. Appl. Physiol. (Respir. Environ. Exercise Physiol.) 55:569-577.

29. Kwawakami, Y, F. Kishi, H. Yamamoto, and K. Miyamoto. 1983. Relation of oxygen delivery, mixed venous oxygenation, and pulmonary hemodynamics to prognosis in chronic obstructive pulmonary disease. N. Engl. J. Med. 308:1045-1049.
30. Benumof, J., and E. Wahrenbrock. 1975. Blunted hypoxic pulmonary vasoconstriction by increased lung vascular pressures. J. Appl. Physiol. 38:846-850.

31. Dawson, D. A. 1984. Role of pulmonary vasomotion in physiology of the lung. Physiol. Rev. 64:544-616.

32. Adams, R. J., and A. Schwarz. 1980. Comparative mechanisms for contraction of cardiac and skeletal muscle. Chest. 78(Suppl.):123139.

33. Lipasti, J. A., T. J. Nevalainen, K. A. Alanen, and M. A. Tolvanen. 1984. Anaerobic glycolysis and the development of ischaemic contracture in isolated rat heart. Cardiovasc. Res. 18:145-148.

34. Momomura, S., A. B. Bradley, and W. Grossman. 1984. Left ventricular diastolic presssure-length relations and end-diastolic distensibility in dogs with coronary stenoses. Circ. Res. 55:203-214.

35. Paulus, W. J., W. Grossman, T. Serizawa, P. D. Bourdillon, A. Pasipoularides, and I. Mirsky. 1985. Different effects of two types of ischemia on myocardial systolic and diastolic function. Am. J. Physiol. 248(Heart Circ. Physiol. 17):H719-H728.

36. Paulus, W. J., T. Serizawa, and W. Grossman. 1982. Altered left ventricular diastolic properties during pacing induced ischemia in dogs with coronary stenoses. Potentiation by caffeine. Circ. Res. 50:218-227.

37. Bing, O. H. L., W. W. Brooks, and J. V. Messer. Effects of isoproterenol on heart muscle performance during myocardial hypoxia. $J$. Mol. Cell. Cardiol. 4:319-328.

38. Brutsaert, D. L., F. E. Rademakers, and S. U. Sys. 1984. Triple control of relaxation: implications in cardiac disease. Circulation. 69: 190-196.

39. Olsen, C. O., D. E. Attaria, R. N. Jones, R. C. Hill, J. D. Sink, K. L. Lee, and A. S. Wechsler. 1981. The coronary pressure-flow determinants of left ventricular compliance in dogs. Circ. Res. 49:856-865. 